\title{
Simultaneous Determination of Triterpenoid Saponins from Pulsatilla koreana using High Performance Liquid Chromatography Coupled with a Charged Aerosol Detector (HPLC-CAD)
}

\author{
Hyesun Yeom, Joon Hyuk Suh, Jeong-Rok Youm, ${ }^{*}$ and Sang Beom Han* \\ Department of Pharmaceutical Analysis, College of Pharmacy, Chung-Ang University, Seoul 156-756, Korea \\ *E-mail: youmjr@cau.ac.kr(J.R.Youm),hansb@cau.ac.kr (S.B.Han) \\ Received February 3, 2010, Accepted February 25, 2010
}

\begin{abstract}
Several triterpenoid saponins from root of Pulsatilla koreana Nakai (Ranunculaceae) were studied and their biological activities were reported. It is difficult to analyze triterpenoid saponins using HPLC-UV due to the lack of chromophores. So, evaporative light scattering detection (ELSD) is used as a valuable alternative to UV detection. More recently, a charged aerosol detection (CAD) has been developed to improve the sensitivity and reproducibility of ELSD. In this study, we developed and validated a novel method of high performance liquid chromatography coupled with a charged aerosol detector for the simultaneous determination of four triterpenoid saponins: pulsatilloside $\mathrm{E}$, pulsatilla saponin $\mathrm{H}$, anemoside $\mathrm{B}_{4}$ and cussosaponin C. Analytes were separated by the Supelco Ascentis ${ }^{\circledR}$ Express C18 column $(4.6 \mathrm{~mm} \times$ $150 \mathrm{~mm}, 2.7 \mu \mathrm{m}$ ) with gradient elution of methanol and water at a flow rate of $0.8 \mathrm{~mL} / \mathrm{min}$ at $30^{\circ} \mathrm{C}$. We examined various factors that could affect the sensitivity of the detectors, including various concentrations of additives, the $\mathrm{pH}$ of the mobile phase, and the $\mathrm{CAD}$ range. Linear calibration curves were obtained within the concentration ranges of 2 - 200 $\mu \mathrm{g} / \mathrm{mL}$ for pulsatilloside $\mathrm{E}$, anemoside $\mathrm{B}_{4}$ and cussosaponin $\mathrm{C}$, and $5-500 \mu \mathrm{g} / \mathrm{mL}$ for pulsatilla saponin $\mathrm{H}$ with correlation coefficient $\left(\mathrm{R}^{2}\right)$ greater than 0.995 . The limit of detection (LOD) and quantification (LOQ) were $0.04-0.2$ and $2-5 \mu \mathrm{g} / \mathrm{mL}$, respectively. The validity of the developed HPLC-CAD method was confirmed by satisfactory values of linearity, intra- and inter-day accuracy and precision. This method could be successfully applied to quality evaluation, quality control and monitoring of Pulsatilla koreana.
\end{abstract}

Key Words: High performance liquid chromatography, Charged aerosol detection, Pulsatilla koreana, Triterpenoid saponins, Method validation

\section{Introduction}

Pulsatilla Radix, the dried root of Pulsatilla koreana Nakai (Ranunculaceae), is a traditional Korean herbal medicine used to treat leucorrhoea, dysentery, and scrofula, and as an antiparasitic, anti-inflammatory and contraceptive agent. ${ }^{1}$ Pulsatilla Radix has been investigated extensively, and ranunculin, anemonin, protoanemonin, and various saponins and triterpenes have been isolated. ${ }^{2-7}$ Previous chemical and pharmacological investigations have revealed that triterpenoid saponins are its main biologically active components, exhibiting antitumor, cytotoxic, cognition-enhancing and other effects. ${ }^{8-10}$ Recently, the saponin fraction of $P$. koreana was reported to improve memory impairments, and clinical trials for treatment of Alzheimer's disease using this fraction are in progress in Korea. ${ }^{11,12}$

As noted above, triterpenoid saponins represent the major

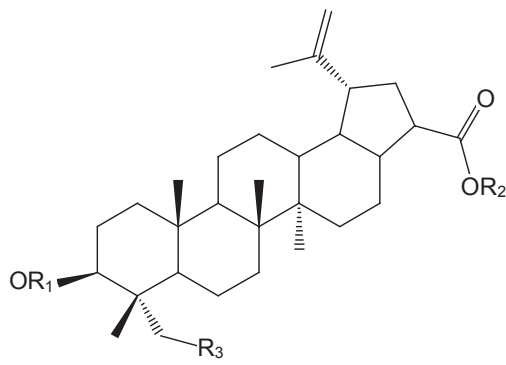

Lupane-type

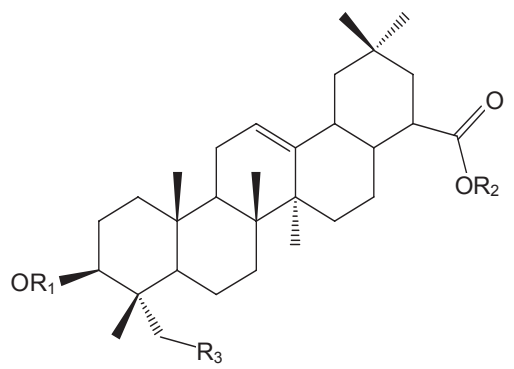

Oleanane-type

\begin{tabular}{|c|c|c|c|c|}
\hline Name & Aglycon & $\mathrm{R}^{1}$ & $\mathrm{R}^{2}$ & $\mathrm{R}^{3}$ \\
\hline Pulsatilloside E & lupane & $-\operatorname{ara}[(2 \rightarrow 1) \mathrm{rha}][(4 \rightarrow 1) \mathrm{glc}]$ & $-\operatorname{glc}(6 \rightarrow 1) \operatorname{glc}(4 \rightarrow 1)$ rha & $-\mathrm{OH}$ \\
\hline Pulsatilla saponin $\mathrm{H}$ & oleanane & $-\operatorname{ara}[(2 \rightarrow 1) \mathrm{rha}][(4 \rightarrow 1) \mathrm{glc}]$ & $-\operatorname{glc}(6 \rightarrow 1) \operatorname{glc}(4 \rightarrow 1)$ rha & $-\mathrm{OH}$ \\
\hline Anemoside $\mathrm{B}_{4}$ & lupane & $-\operatorname{ara}(2 \rightarrow 1)$ rha & $-\operatorname{glc}(6 \rightarrow 1) \operatorname{glc}(4 \rightarrow 1)$ rha & $-\mathrm{OH}$ \\
\hline Cussosaponin C & lupane & $-\operatorname{ara}(2 \rightarrow 1)$ rha & $-\operatorname{glc}(6 \rightarrow 1) \operatorname{glc}(4 \rightarrow 1)$ rha & $-\mathrm{H}$ \\
\hline
\end{tabular}

Figure 1. Structures of the four triterpenoid saponins analyzed in this study. (ara : $\alpha$-L-arabinose, rha : $\alpha$-L-rhamnose, glc : $\beta$-D-glucose) 
biological activities of $P$. koreana and these saponins could be used as chemical markers for quality control. There are many reports of analysis of saponins such as ginsenosides, but few methods are published ${ }^{13}$ for the qualitative or quantitative analysis of polyglycoside triterpenoid saponins such as pulsatilloside $\mathrm{E}$, pulsatilla saponin $\mathrm{H}$, anemoside $\mathrm{B}_{4}$ and cussosaponin $\mathrm{C}$ from $P$. koreana (Figure 1). Cheng et al. ${ }^{14}$ developed a LC-ESI$\mathrm{MS}^{\mathrm{n}}$ method for differentiation of two types of triterpenoid saponins by formation of silver-saponin complexes in positive ion mode. The identified saponins could be divided into lupineand oleanane-type, but were not quantified for quality control of Pulsatilla chinensis.

In the absence of a chromophore, evaporative light scattering detector (ELSD) or charged aerosol detector (CAD) could be alternatives to the UV detector in detection of triterpenoid saponins. ${ }^{15,16}$ Both ELSD and CAD are universal detectors with stable baseline for the analysis of non-chromophoric and nonvolatile compounds. Mass spectrometric detection can be also employed for non- or weak-UV-absorbing compounds, but this technique is still expensive for widespread routine use and is less robust due to the complex ionization process. Therefore, the use of ELSD and CAD is continuously increasing for the analysis of various compounds. ${ }^{17-20}$

Both detection methods share similar principles and use a pneumatic nebulizer, a heated tube where the solvent evaporates and a detection chamber. However, instead of measuring light scattering as in ELSD, CAD uses an electrometer to measure the electrical charge of charged particles using a secondary stream of nitrogen passing through a corona discharge needle. ${ }^{16}$ The principle of ELSD was described in the 1970s whereas $\mathrm{CAD}$ is a more recent development. ${ }^{21}$ Generally, CAD is more sensitive than ELSD ${ }^{16}$ but this difference in sensitivity is strongly influenced by the HPLC mobile phase additives. ${ }^{22}$ Recently, there was a report of simultaneous detection of triterpenoid saponins from $P$. koreana using HPLC-ELSD, ${ }^{13}$ however the sensitivity was not good. To the best of our knowledge, CAD has not been used for the analysis of active saponin constituents of $P$. koreana extract.

In the present study, we developed a HPLC-CAD method that was used to simultaneously analyze four triterpenoid saponins (pulsatilloside $\mathrm{E}$, pulsatilla saponin $\mathrm{H}$, anemoside $\mathrm{B}_{4}$ and cussosaponin C) in P. koreana for the first time. Optimized chromatographic conditions resulted in the complete resolution of all four compounds with high sensitivity within $26 \mathrm{~min}$ of analysis. The validity of the developed HPLC-CAD method was confirmed by estimating linearity, precision, accuracy, limit of detection (LOD) and limit of quantification (LOQ).

\section{Experimental}

Chemicals and materials. Four triterpenoid saponins, pulsatilloside $\mathrm{E}$, pulsatilla saponin $\mathrm{H}$, anemoside $\mathrm{B}_{4}$ and cussosaponin $\mathrm{C}$, were provided by the College of Pharmacy, Seoul National University (Seoul, South Korea). The purity of these analytes was determined to be more than $99 \%$ by normalization of the peak areas detected by HPLC-ELSD. Acetic acid ( $\geq 99.7 \%$ ) and ammonium formate $(\geq 97 \%)$ were purchased from Sigma-Aldrich (St. Louis, MO, USA). Formic acid and ammonium ace- tate $(\geq 98 \%)$ were purchased from Fluka (Buchs, Switzerland) and Merck (Darmstadt, Germany), respectively. HPLC-grade acetonitrile, methanol and water were purchased from Fisher Scientific (Fair Lawn, NJ, USA). Nylon membrane filters (0.45 $\mu \mathrm{m})$ were purchased from Whatman (Maidstone, England).

HPLC-CAD analysis. All HPLC experiments were performed on a PerkinElmer series 200 pump (Waltham, MA, USA), a PerkinElmer series 200 column oven and a Waters 717 plus autosampler (Milford, MA, USA) equipped with an ESA Corona charged aerosol detector (Chelmsford, MA, USA). Analytes were separated on a Supelco Ascentis ${ }^{\circledR}$ Express C18 column (4.6 mm $\times 150 \mathrm{~mm}, 2.7 \mu \mathrm{m}$, Bellefonte, PA, USA) and a Phenomenex Security Guard C18 column $(4.0 \times 3.0 \mathrm{~mm}$, Torrance, CA, USA). The binary gradient system consisted of methanol (eluent A) and water (eluent B) with fixed flow rate of $0.8 \mathrm{~mL} /$ $\mathrm{min}$. The linear gradient elution was performed with the following elution program: 0 - $12 \mathrm{~min}, 50 \%$ A to $65 \% \mathrm{~A} ; 12$ - $20 \mathrm{~min}$, $65 \% \mathrm{~A} ; 20-21 \mathrm{~min}, 65 \%$ A to $100 \% \mathrm{~A} ; 21-26 \mathrm{~min}, 100 \% \mathrm{~A}$ and then returning to $50 \%$ A for column equilibration. All eluents were filtered through a $0.45-\mu \mathrm{m}$ polytetrafluoroethylene (PTFE) membrane filter. The injection volume was $20 \mu \mathrm{L}$, and the column and autosampler temperatures were kept at $30^{\circ} \mathrm{C}$ and $4{ }^{\circ} \mathrm{C}$, respectively. The nitrogen inlet pressure for the $\mathrm{CAD}$ was set to $35 \mathrm{psi}$ with a CAD range of $200 \mathrm{pA}$. The data were obtained with the software, Empower (Ver. 5.00.00.00, Waters).

Preparation of standard solutions and sample solutions. The stock solutions $(1,000 \mu \mathrm{g} / \mathrm{mL})$ of four saponins (pulsatilloside E, pulsatilla saponin $\mathrm{H}$, anemoside $\mathrm{B}_{4}$, and cussosaponin $\mathrm{C}$ ) were prepared by dissolving $3 \mathrm{mg}$ of each standard into $3 \mathrm{~mL}$ of methanol and filtering through $0.45-\mu \mathrm{m}$ nylon membrane filters; these solutions were stored at $-70{ }^{\circ} \mathrm{C}$ until further use. Stock solutions were mixed to obtain the desired concentrations. The mixed stock solutions were then diluted in $50 \%$ methanol in the concentration ranges of $2-200 \mu \mathrm{g} / \mathrm{mL}(2,4,8,20,40,80$ and $200 \mu \mathrm{g} / \mathrm{mL}$ ) for pulsatilloside $\mathrm{E}$, anemoside $\mathrm{B}_{4}$, and cussosaponin C, and $5-500 \mu \mathrm{g} / \mathrm{mL}(5,10,20,50,100,200$ and 500 $\mu \mathrm{g} / \mathrm{mL}$ ) for pulsatilla saponin $\mathrm{H}$. All solutions were stored at 5 ${ }^{\mathrm{o}} \mathrm{C}$.

Pulsatilla Radix sample was finely ground to powder and about $5.0 \mathrm{~g}$ was weighed accurately. One hundred milliliters of $50 \%$ methanol was used for extraction at $90{ }^{\circ} \mathrm{C}$, refluxing for 2 hours. The extract was centrifuged and the supernatant was filtered and evaporated under vacuum, and then suspended to $100 \mathrm{~mL}$ with $50 \%$ methanol in a volumetric flask. The final sample solution was filtered through $0.45-\mu$ m nylon membrane filter and analyzed with HPLC.

Analytical method validation. The calibration curves of the four triterpenoid saponins were constructed by plotting the logarithm of the peak areas versus the logarithm of seven different concentrations of each saponin. The limit of detection (LOD) and limit of quantification (LOQ) were calculated based on signal-to-noise ratios of $\geq 3$ and $\geq 10$, respectively.

The intra- and inter-day accuracy and precision were examined within the linear range of the calibration curve from 2 - 200 $\mu \mathrm{g} / \mathrm{mL}$ for pulsatilloside $\mathrm{E}$, anemoside $\mathrm{B}_{4}$, and cussosaponin $\mathrm{C}$, and 5 - $500 \mu \mathrm{g} / \mathrm{mL}$ for pulsatilla saponin $\mathrm{H}$. The intra-day accuracy and precision was determined within one day by analyzing five replicates of the four concentrations of the standard 
solution, while, for the inter-day accuracy and precision, the four concentrations of the standard solution was analyzed for five sequential days. The accuracy was expressed as the observed value relative to the true value and the precision was expressed as relative standard deviation (coefficient of variation, CV).

The recovery assay was determined according to the standard addition procedure at three different concentration levels $(20$, $50,100 \mu \mathrm{g} / \mathrm{mL}$ for pulsatilloside $\mathrm{E}$, anemoside $\mathrm{B}_{4}$, and cussosaponin $\mathrm{C}$, and 40,100, $200 \mu \mathrm{g} / \mathrm{mL}$ for pulsatilla saponin $\mathrm{H}$ ). Five grams of sample was spiked with four standards and prepared as described in the previous section. Recovery was evaluated by calculating the ratios of the amount difference between standard-spiked sample and sample versus standard alone which concentration was same as those spiked into the sample. Three determinations were replicated for each addition level.

\section{Results and Discussion}

Optimization of HPLC method. The response of the charged aerosol detector (CAD) is influenced by the size of the mist aerosols generated in the nebulizer, ${ }^{21}$ as it is in ELSD. Since the aerosol size is dependent on the mobile phase density, viscosity and interfacial tension, the CAD is sensitive to the type and concentration of buffer added to the mobile phase. Appropriate mobile phase buffers for CAD are volatile additives such as acetic acid, formic acid, acetate buffer and formate buffer.

The influence of various concentrations of acids and buffers, including acetic acid $(0.01,0.05$ and $0.1 \%, \mathrm{v} / \mathrm{v})$, formic acid $(0.01,0.05$ and $0.1 \%, \mathrm{v} / \mathrm{v})$, ammonium acetate buffer $(0.1,0.5$,
$1,2$ and $5 \mathrm{mM})$ and ammonium formate buffer $(0.1,0.5,1,2$ and $5 \mathrm{mM}$ ), were tested at $\mathrm{pH} 3.0,4.0$ and 5.0 in order to optimize the mobile phase. In this study, the optimal mobile phase of the CAD system was evaluated by comparing the peak areas at the same concentrations of the four saponins.

The sensitivity of the CAD was reduced by increasing the acid concentration in the mobile phase and was slightly better with acetic acid than with formic acid (Figure 2). However, the best peak shapes and peak areas were achieved when no acid (neither acetic acid nor formic acid) was added. The effects of ammonium acetate and ammonium formate buffer concentration on the CAD response were also tested (Figure 3 ). In both cases, the peak areas of all triterpenoid saponins were diminished by increasing the buffer concentration. The peak area of pulsatilla saponin $\mathrm{H}$ was reduced markedly by addition of acids and buffers. The peak area decrease with $5 \mathrm{mM}$ ammonium acetate buffer was about $27 \%$ compared to water (no buffer salts). Similarly, the response of the CAD was improved by decreasing the buffer concentrations, and the best sensitivity was obtained with the mobile phase that had no buffer salts.

Optimal concentrations of ammonium acetate and ammonium formate at $\mathrm{pH} 4.0$ were selected first and then $\mathrm{pH}$ conditions were further tested at $\mathrm{pH} 4.0$ and 5.0 for ammonium acetate and at $\mathrm{pH} 3.0$ and 4.0 for ammonium formate. Excluding the mobile phase with no additives, the optimal concentrations of ammonium acetate and ammonium formate were $0.1 \mathrm{mM}$ and the optimal sensitivity was achieved at $\mathrm{pH} 4.0$ for both buffer salts.

As a result, mobile phase modifiers such as acetic acid, formic
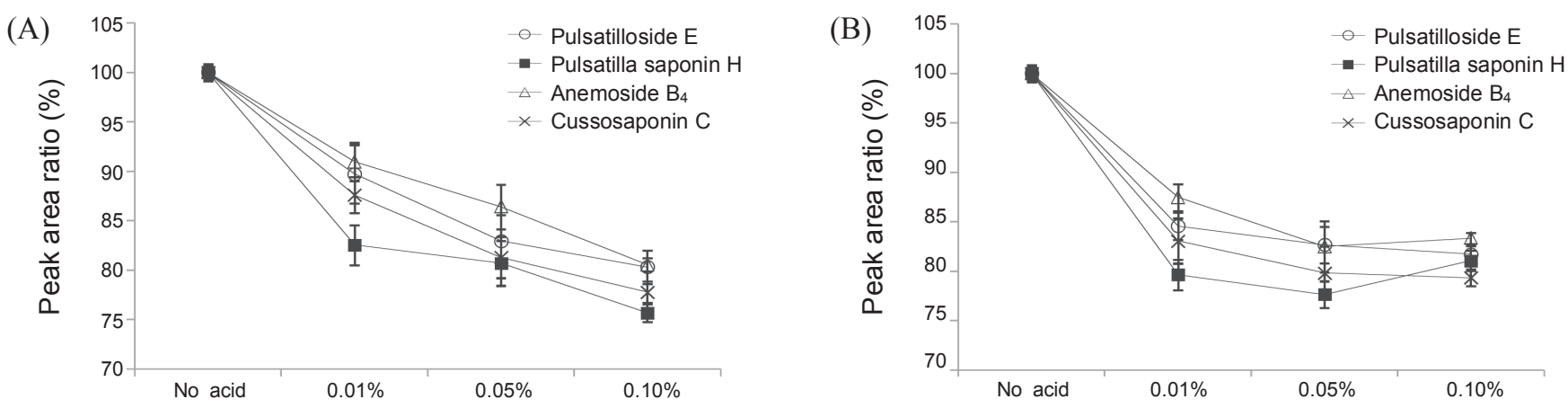

Figure 2. Comparison of the peak areas with different concentrations of $(A)$ acetic acid and (B) formic acid $(n=3)$.
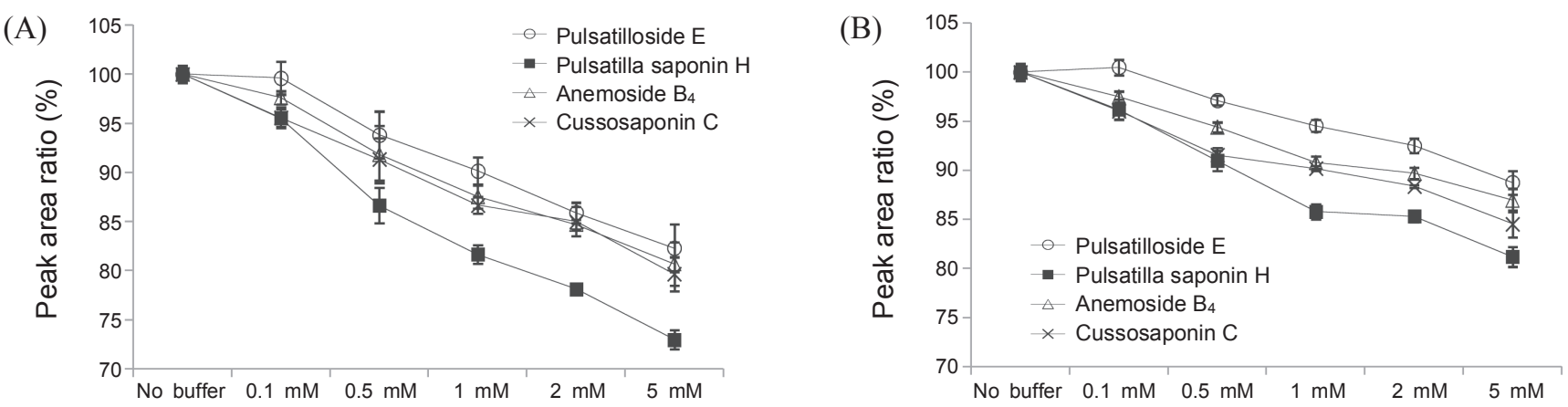

Figure 3. Comparison of the peak areas with different concentrations of (A) ammonium acetate buffer (pH 4.0) and (B) ammonium formate buffer ( $\mathrm{pH} 4.0)(\mathrm{n}=3)$. 


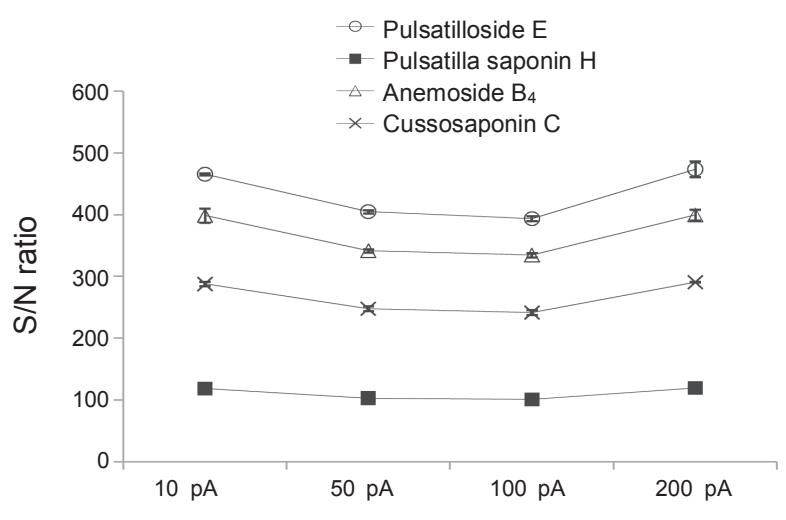

Figure 4. Comparison of the $\mathrm{S} / \mathrm{N}$ ratios for different $\mathrm{CAD}$ ranges $(\mathrm{n}=3)$.

acid, acetate buffer and formate buffer did not help the detector response in the determination of the four triterpenoid saponins in the CAD system. More studies are needed to fully investigate the effects of these additives on the response of the CAD system.

Optimization of the CAD range. The range of the detector signal output is an important parameter that affects the sensitivity of CAD. Therefore, the CAD signal was set at 10, 50, 100 and $200 \mathrm{pA}$ to test the effects on sensitivity by determining the signal-to-noise $(\mathrm{S} / \mathrm{N})$ ratios of the four saponins (Figure 4$)$. The high responses were obtained in the lowest $\mathrm{pA}$ ranges, but these values were practically unusable due to the low $\mathrm{S} / \mathrm{N}$ ratio. The highest $\mathrm{S} / \mathrm{N}$ ratios were obtained with $10 \mathrm{pA}$ and $200 \mathrm{pA}$, but $200 \mathrm{pA}$ was slightly better than $10 \mathrm{pA}$ because of the high noise at $10 \mathrm{pA}$. As a result, the optimum performance with CAD could be achieved with a CAD signal of $200 \mathrm{pA}$.

One of the advantages of the CAD system is its simple operation. However, there is only one controllable parameter, the $\mathrm{CAD}$ range, in the $\mathrm{CAD}$ system, which limits the chance to optimize the detector performance by changing the temperature, nebulizing gas pressure and voltage of corona charge.

Optimization of separation. Ascentis ${ }^{\circledR}$ Express column, which is packed with unique 2.7 - $\mu \mathrm{m}$ fused-core particles, ${ }^{23}$ showed the best performance, i.e., better resolution and peak sharpness with a low back pressure compared to other conventional particulate columns. ${ }^{24-26}$ Accordingly, almost all constituents of $P$. koreana extract, including the four triterpenoid saponins, were fairly well resolved within 26 min of elution (Figure 5).

For the consistent response of saponins with $\mathrm{CAD}$, isocratic elution is preferred due to its constant mobile phase composition. In gradient elution, the CAD response will vary with the change of mobile phase composition, which is a disadvantage of the CAD system. ${ }^{22}$ However, in this study, various mobile phase proportions and gradient durations were tested for the complete separation of $P$. koreana extract. An optimum mobile phase in gradient mode was subsequently found as described in the Experimental section. Neither the flow rate of the mobile phase nor the column temperature significantly influenced the separation and CAD response.

Validation of the developed analytical method: linearity, intra- and inter-day accuracy, precision, limit of detection (LOD), limit of quantification (LOQ) and recovery. All of the validation processes were carried out in accordance with the guidelines
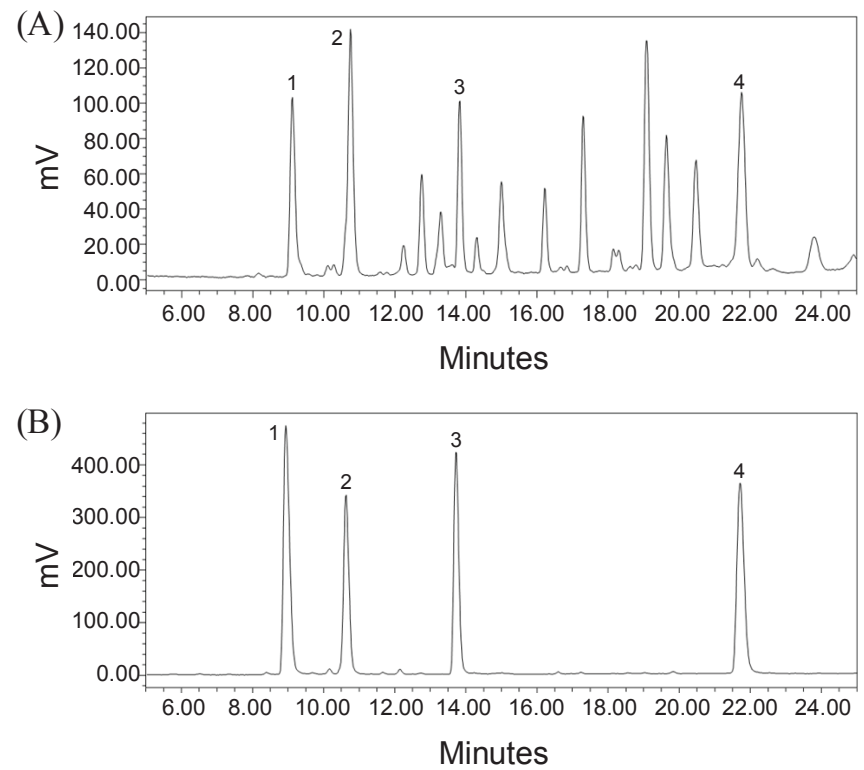

Figure 5. HPLC-CAD chromatograms of (A) extract from Pulsatilla koreana and (B) standards at concentrations of $200 \mu \mathrm{g} / \mathrm{mL}$ for pulsatilloside $\mathrm{E}$, anemoside $\mathrm{B}_{4}$, cussosaponin $\mathrm{C}$ and $500 \mu \mathrm{g} / \mathrm{mL}$ for pulsatilla saponin $\mathrm{H}$ (compound numbering: 1. pulsatilloside E, 2. pulsatilla saponin $\mathrm{H}, 3$. anemoside $\mathrm{B}_{4}$, and 4 . cussosaponin $\mathrm{C}$ ).

prescribed at the International Conference on Harmonization (ICH). ${ }^{27}$ The developed method was validated by assessing the linearity, intra- and inter-day accuracy and precision, limit of detection (LOD) and limit of quantification (LOQ).

Like an ESLD, the response of CAD is not directly linear over a broad concentration range. Therefore, linear regression curves for the triterpenoid saponin standards were constructed on a log-log scale for signal response versus concentration. Good linearity (correlation coefficients, $\mathrm{R}^{2}$, between 0.995 and 0.996) was obtained for the four triterpenoid saponins within the linear range of $2-200 \mu \mathrm{g} / \mathrm{mL}$ for pulsatilloside $\mathrm{E}$, anemoside $\mathrm{B}_{4}$ and cussosaponin $\mathrm{C}$, and $5-500 \mu \mathrm{g} / \mathrm{mL}$ for pulsatilla saponin $\mathrm{H}$ (Table 1). The slopes were similar, ranging from $0.787-0.851$ even for the lupine-type (pulsatilloside $\mathrm{E}$, anemoside $\mathrm{B}_{4}$, and cussosaponin C) and oleanane-type (pulsatilla saponin H). This result showed that $\mathrm{CAD}$ response was relatively independent of compound structure, ${ }^{28}$ within certain variations, unlike other "universal" detectors (RI, ELSD, MS, etc.) in which detection responses are dependent on the chemical structure of the molecule being tested.

The limit of detection (LOD) was defined as the lowest concentration of the analyte that can be detected greater than three times the signal-to-noise ratio $(\mathrm{S} / \mathrm{N} \geq 3)$, and the limit of quantification (LOQ) was defined as the concentration of analyte that corresponded to ten times greater the signal-to-noise ratio ( $\mathrm{S} / \mathrm{N} \geq 10$ ) with precision of $\leq 20 \%$ and accuracy between 80 $120 \%$. The LODs of the four saponins were $0.04-0.20 \mu \mathrm{g} / \mathrm{mL}$, whereas the LOQs of the four triterpenoid saponins were 2.0 $\mu \mathrm{g} / \mathrm{mL}$ for pulsatilloside $\mathrm{E}$, anemoside $\mathrm{B}_{4}$, and cussosaponin $\mathrm{C}$ and $5.0 \mu \mathrm{g} / \mathrm{mL}$ for pulsatilla saponin $\mathrm{H}$ (Table 1). Compared to those reported by Lee et al., ${ }^{13}$ our LOQ values improved by about 4-, 12-, 15- and 17-fold for pulsatilla saponin H, cusso- 
Table 1. Calibration curve parameters, LOD and LOQ for the assay of four triterpenoid saponins $(n=5)$

\begin{tabular}{lccccc}
\hline \multicolumn{1}{c}{ Compounds } & $\begin{array}{c}\text { Linear range } \\
(\mu \mathrm{g} / \mathrm{mL})\end{array}$ & \multicolumn{1}{c}{ Regression equation $^{a}$} & $\begin{array}{c}\text { Correlation coefficient } \\
\left(\mathrm{R}^{2}\right)\end{array}$ & $\begin{array}{c}\text { LOD } \\
(\mu \mathrm{g} / \mathrm{mL})\end{array}$ & $\begin{array}{c}\text { LOQ } \\
(\mu \mathrm{g} / \mathrm{mL})\end{array}$ \\
\hline Pulsatilloside E & $2 \sim 200$ & $\mathrm{y}=(0.787 \pm 0.014) \mathrm{x}+(4.987 \pm 0.034)$ & 0.996 & 0.04 & 2 \\
Pulsatilla saponin $\mathrm{H}$ & $5 \sim 500$ & $\mathrm{y}=(0.846 \pm 0.018) \mathrm{x}+(4.334 \pm 0.053)$ & 0.996 & 0.20 & 5 \\
Anemoside $\mathrm{B}_{4}$ & $2 \sim 200$ & $\mathrm{y}=(0.810 \pm 0.0236) \mathrm{x}+(4.810 \pm 0.054)$ & 0.995 & 0.05 & 2 \\
Cussosaponin $\mathrm{C}$ & $2 \sim 200$ & $\mathrm{y}=(0.851 \pm 0.0130) \mathrm{x}+(4.811 \pm 0.033)$ & 0.995 & 0.07 & 2 \\
\hline
\end{tabular}

$\overline{\mathrm{a}}=\log$ (peak area), $\mathrm{x}=\log$ (concentration of standards, $\mu \mathrm{g} / \mathrm{mL})$

Table 2. Analytical results of intra- and inter-day accuracy and precision $(n=5)$

\begin{tabular}{|c|c|c|c|c|c|}
\hline \multirow{2}{*}{ Compounds } & \multirow{2}{*}{ Conc. $(\mu \mathrm{g} / \mathrm{mL})$} & \multicolumn{2}{|c|}{ Accuracy $(\%)$} & \multicolumn{2}{|c|}{ Precision $(\mathrm{CV}, \%)$} \\
\hline & & Intra-day & Inter-day & Intra-day & Inter-day \\
\hline \multirow{4}{*}{ Pulsatilloside E } & 2 & 85.38 & 84.77 & 6.24 & 6.68 \\
\hline & 8 & 103.99 & 103.17 & 0.97 & 1.38 \\
\hline & 40 & 101.98 & 102.59 & 0.55 & 1.05 \\
\hline & 200 & 97.42 & 97.82 & 0.21 & 0.15 \\
\hline \multirow{4}{*}{ Pulsatilla saponin $\mathrm{H}$} & 5 & 94.16 & 92.65 & 2.48 & 3.97 \\
\hline & 20 & 102.37 & 102.07 & 1.08 & 0.97 \\
\hline & 100 & 102.37 & 102.37 & 0.38 & 0.84 \\
\hline & 500 & 97.82 & 98.17 & 0.32 & 0.12 \\
\hline \multirow{4}{*}{ Anemoside $\mathrm{B}_{4}$} & 2 & 82.62 & 88.70 & 1.16 & 6.62 \\
\hline & 8 & 103.60 & 104.65 & 1.45 & 3.07 \\
\hline & 40 & 102.62 & 103.15 & 0.59 & 1.15 \\
\hline & 200 & 97.46 & 97.83 & 0.54 & 0.42 \\
\hline \multirow{4}{*}{ Cussosaponin C } & 2 & 84.39 & 85.53 & 1.07 & 3.52 \\
\hline & 8 & 103.33 & 104.27 & 1.98 & 1.32 \\
\hline & 40 & 103.01 & 103.32 & 0.69 & 0.92 \\
\hline & 200 & 97.22 & 97.69 & 0.54 & 0.26 \\
\hline
\end{tabular}

Table 3. Recovery assay of four triterpenoid saponins $(n=3)$

\begin{tabular}{|c|c|c|c|c|c|}
\hline \multirow{2}{*}{ Compounds } & \multirow{2}{*}{$\begin{array}{l}\text { Initial concentration } \\
\qquad(\mu \mathrm{g} / \mathrm{mL})\end{array}$} & \multirow{2}{*}{$\begin{array}{l}\text { Amount added } \\
(\mu \mathrm{g} / \mathrm{mL})\end{array}$} & \multirow{2}{*}{$\begin{array}{l}\text { Concentration found } \\
\qquad(\mu \mathrm{g} / \mathrm{mL})\end{array}$} & \multicolumn{2}{|c|}{ Recovery (\%) } \\
\hline & & & & Mean & $\mathrm{RSD}^{a}$ \\
\hline \multirow{3}{*}{ Pulsatilloside E } & \multirow{3}{*}{22.80} & 20 & 42.11 & 96.58 & 2.47 \\
\hline & & 50 & 72.16 & 98.72 & 1.43 \\
\hline & & 100 & 120.18 & 97.38 & 0.87 \\
\hline \multirow{3}{*}{ Pulsatilla saponin $\mathrm{H}$} & \multirow{3}{*}{134.84} & 40 & 175.66 & 102.05 & 5.79 \\
\hline & & 100 & 234.17 & 99.33 & 1.58 \\
\hline & & 200 & 325.58 & 95.37 & 1.13 \\
\hline \multirow{3}{*}{ Anemoside $\mathrm{B}_{4}$} & \multirow{3}{*}{23.05} & 20 & 42.49 & 97.19 & 1.09 \\
\hline & & 50 & 72.91 & 99.72 & 2.15 \\
\hline & & 100 & 118.07 & 95.02 & 0.52 \\
\hline \multirow{3}{*}{ Cussosaponin C } & \multirow{3}{*}{37.22} & 20 & 57.46 & 101.21 & 2.76 \\
\hline & & 50 & 87.36 & 100.28 & 1.12 \\
\hline & & 100 & 136.23 & 99.01 & 1.15 \\
\hline
\end{tabular}

${ }^{a}$ Relative Standard Deviation

saponin $\mathrm{C}$, anemoside $\mathrm{B}_{4}$ and pulsatilloside $\mathrm{E}$, respectively.

The intra- and inter-day accuracy and precision were obtained by analyzing five replicates of the four saponins at four different concentrations. The intra-day and inter-day accuracies ranged from 82.62 to $103.99 \%$ and 84.77 to $104.65 \%$, respectively.
The intra-day and inter-day precisions were within the range of $0.21-6.24 \%$ and $0.12-6.68 \%$, respectively. All the measured precision and accuracy values fell within the acceptable range, confirming the validity of our developed method (Table 2). Therefore, the established HPLC-CAD method could be applied 
to the quantitative evaluation of the four triterpenoid saponins in P. koreana as chemical markers for quality control.

The recoveries according to standard addition procedure at three different concentrations were calculated on repeated experiments $(n=3)$. The mean recoveries of all of the tested samples were from 95.02 to $102.05 \%$ (Table 3 ).

\section{Conclusion}

To our knowledge, this is the first report on the simultaneous determination of four triterpenoid saponins, pulsatilloside $\mathrm{E}$, pulsatilla saponin $\mathrm{H}$, anemoside $\mathrm{B}_{4}$ and cussosaponin $\mathrm{C}$, from Pulsatilla koreana using high performance liquid chromatography coupled with a charged aerosol detection system (HPLC$\mathrm{CAD}$ ). The method provided excellent resolution and sensitivity for the four triterpenoid saponins within 26 min of analysis time. The developed method was validated by assessing parameters such as linearity, intra- and inter-day accuracy and precision, limit of detection, limit of quantification and recovery. Good linearity was obtained for analytes within the linear ranges of the calibration curves, and the accuracy and precision obtained were within the acceptable ranges. The limits of quantification were also examined and the values were better than those previously published. In conclusion, we propose that this method could be used routinely for quality evaluation, quality control and monitoring of Pulsatilla koreana.

Acknowledgments. This research was supported by the Chung-Ang University Research Scholarship Grant in 2008.

\section{References}

1. Bae, K. H. The Medicinal Plants of Korea; Kyo-Hak Press: Seoul, 1999, p 139.

2. Zhang, X. Q.; Liu, A. R.; Xu, L. X. Yao Hsueh Hsueh Pao 1990, 25, 932.

3. Ye, W. C.; Ou, B. X.; Ji, N. N.; Zhao, S. X.; Ye, T.; McKervey, M. A.; Stevenson, P. Phytochemistry 1995, 39, 937.

4. Ye, W. C.; Nine, N. J.; Shou, X. Z.; Jing, H. L.; Tao, Y.; McKervey,
M. A.; Stevenson, P. Phytochemistry 1996, 42, 799.

5. Mimaki, Y.; Yokosuka, A.; Kuroda, M.; Hamanaka, M.; Sakuma, C.; Sashida, Y. J. Nat. Prod. 2001, 64, 1226.

6. Harinantenaina, L.; Kasai, R.; Yamasaki, K. Chem. Pharm. Bull. 2002, 50, 1290.

7. Bang, S.; Kim, Y.; Lee, J.; Ahn, B. J. Nat. Prod. 2005, 68, 268.

8. Kim, Y.; Kim, S.; You, Y.; Ahn, B. Planta Med. 2002, 68, 271.

9. Kim, Y.; Bang, S.; Lee, J.; Ahn, B. Arch Pharm. Res. 2004, $27,915$.

10. Bang, S.; Lee, J.; Song, G.; Kim, D.; Yoon, M.; Ahn, B. Chem. Pharm. Bull. 2005, 53, 1451.

11. Han, C.; Park, Y.; Jin, D.; Hwang, Y. K.; Oh, K.; Han, J. Brain Res. 2007, 1184, 254.

12. Yoo, H. H.; Lee, S. K.; Lim, S. Y.; Kim, Y.; Kang, M. J.; Kim, E. J.; Park, Y. H.; Im, G.; Lee, B. Y.; Kim, D. J. Pharm. Biomed. Anal. 2008, 48, 1425.

13. Lee, K. Y.; Cho, Y. W.; Park, J.; Lee, D. Y.; Kim, S. H.; Kim, Y. C.; Sung, S. H. Phytochem. Anal. 2010, in press, DOI 10.1002/pca.1201

14. Cheng, L.; Zhang, M.; Zhang, P.; Song, Z.; Ma, Z.; Qu, H. Rapid Commun. Mass Spectrom. 2008, 22, 3783.

15. Ganzera, M.; Stuppner, H. Curr. Pharm. Anal. 2005, 1, 135.

16. Vehovec, T.; Obreza, A. J. Chromatogr. A 2010, 1217, 1549.

17. Shaodong, J.; Lee, W. J.; Ee, J. W.; Park, J. H.; Kwon, S. W.; Lee, J. J. Pharm. Biomed. Anal. 2010, 51, 973.

18. Ramos, R. G.; Libong, D.; Rakotomanga, M.; Gaudin, K.; Loiseau, P. M.; Chaminade, P. J. Chromatogr. A 2008, 1209, 88.

19. Takahashi, K.; Kinugasa, S.; Senda, M.; Kimizuka, K.; Fukushima, K.; Matsumoto, T.; Shibata, Y.; Christensen, J. J. Chromatogr. A 2008, 1193,151.

20. Pistorino, M.; Pfeifer, B. A. Anal. Bioanal. Chem. 2008, 390, 1189.

21. Dixon, R.W.; Peterson, D. S. Anal. Chem. 2002, 74, 2930.

22. Gorecki, T.; Lynen, F.; Szucs, R.; Sandra, P. Anal. Chem. 2006, 78, 3186.

23. Kirkland, J. J.; Truszkowski, F. A.; Dilks, C. H.; Engel, G. S. J. Chromatogr. A 2000, 890, 3.

24. Abrahim, A.; Al-Sayah, M.; Skrdla, P.; Bereznitski, Y.; Chen, Y.; Wu, N. J. Pharm. Biomed. Anal. 2010, 51, 131.

25. Zheng, J.; Patel, D.; Tang, Q.; Markovich, R. J.; Rustum, A. M. J. Pharm. Biomed. Anal. 2009, 50, 815.

26. Song, W.; Pabbisetty, D.; Groeber, E. A.; Steenwyk, R. C.; Fast, D. M. J. Pharm. Biomed. Anal. 2009, 50, 491.

27. Q2B Text on Validation of Analytical Procedures: Methodology, International Conference on Harmonisation (ICH) Guidelines. 1997.

28. Sun, P.; Wang, X.; Alquier, L.; Maryanoff, C. A. J. Chromatogr. A 2008, $1177,87$. 